\title{
Presence of atrial natriuretic factor in normal and hyperplastic human prostate and its relationship with oxytocin localisation
}

\author{
E. Farina-Lipari, D. Lipari, M. Bellafiore, R. Anzalone, F. Cappello, B. Valentino \\ Human Anatomy Section, Department of Experimental Medicine, University of Palermo, Italy
}

(C)2003, European Journal of Histochemistry

In this work, we showed the presence of atrial natriuretic factor (ANF) in human prostate and compared its localisation in normal and hyperplastic conditions. ANF was localised in epithelial and stromal cells, being increased in hyperplasia, mainly in the stromal component. Moreover, we compared ANF and oxytocin positivity in the same glands, focusing on the possible relationship between the paracrine effects of these two hormones.

Key words: ANF, oxytocin, prostatic fluid, prostatic hyperplasia pathogenesis.

Correspondence: Professor Elvira Farina-Lipari, Human Anatomy Section, Department of Experimental Medicine, via del Vespro 129, 90127 Palermo, Italy.

Phone: international +39.091 .6553510$

Fax: international +39.091 .6553580$

E-mail: farina.elviravitt@tiscalinet.it

Paper accepted on June 16, 2002

European Journal of Histochemistry 2003; vol. 47 issue 2 [Apr-Jun]:133-138
- he prostate is a composite organ constituted of glandular and non glandular tissues and is one of the major secretory contributors of the seminal fluid. This function is hormonally regulated and many local biochemical mechanisms are involved. The paracrine role of oxytocin in the modulation of prostatic function has been recently elucidated (Bodanszky et al, 1992; Nicholson 1996); indeed, oxytocin is produced in the prostate under androgen regulation, and it has been shown that it increases the growth of epithelial tissue, muscular tone and contractile activity, being, in turn, involved also in the pathogenesis of benign prostatic hyperplasia (Frayne and Nicholson 1998; Nicholson and Jenkin, 1995). In contrast, the presence and the role of the atrial natriuretic factor (ANF), another peptide with endocrine/paracrine functions in many districts, has not been sufficiently investigated in the male genital tract. ANF is involved in the regulation of the renal excretion of sodium and water and in the relaxation of vascular smooth muscle cells (Currie et al., 1983). Moreover, ANF exerts a number of effects on several glands, such as the inhibition of aldosterone synthesis in adrenal cortical cells (Atarashi et al, 1984), the release of vasopressin from posterior pituitary gland (Samson 1985) and the production of renin in renal cortical cells (Burnett et al., 1984); in addition, ANF has a paracrine/autocrine function during spermiogenesis in rats (Pandey and Orgebin-Crist, 1991). We have previously demonstrated the presence of ANF in the excretory ducts of the rabbit parotid gland (Valentino et al., 1999), postulating the possible paracrine role of this peptide in the regulation of salivary composition. Finally, a number of studies have recently shown a functional interaction between oxytocin and ANF at many sites, such as heart (Favaretto et al 1997), kidney (Soares et al 1999) and myometrium (Carvajal et al 2001).

Since it is known that oxytocin is present in prostatic cells and has a role in the pathogenesis of 

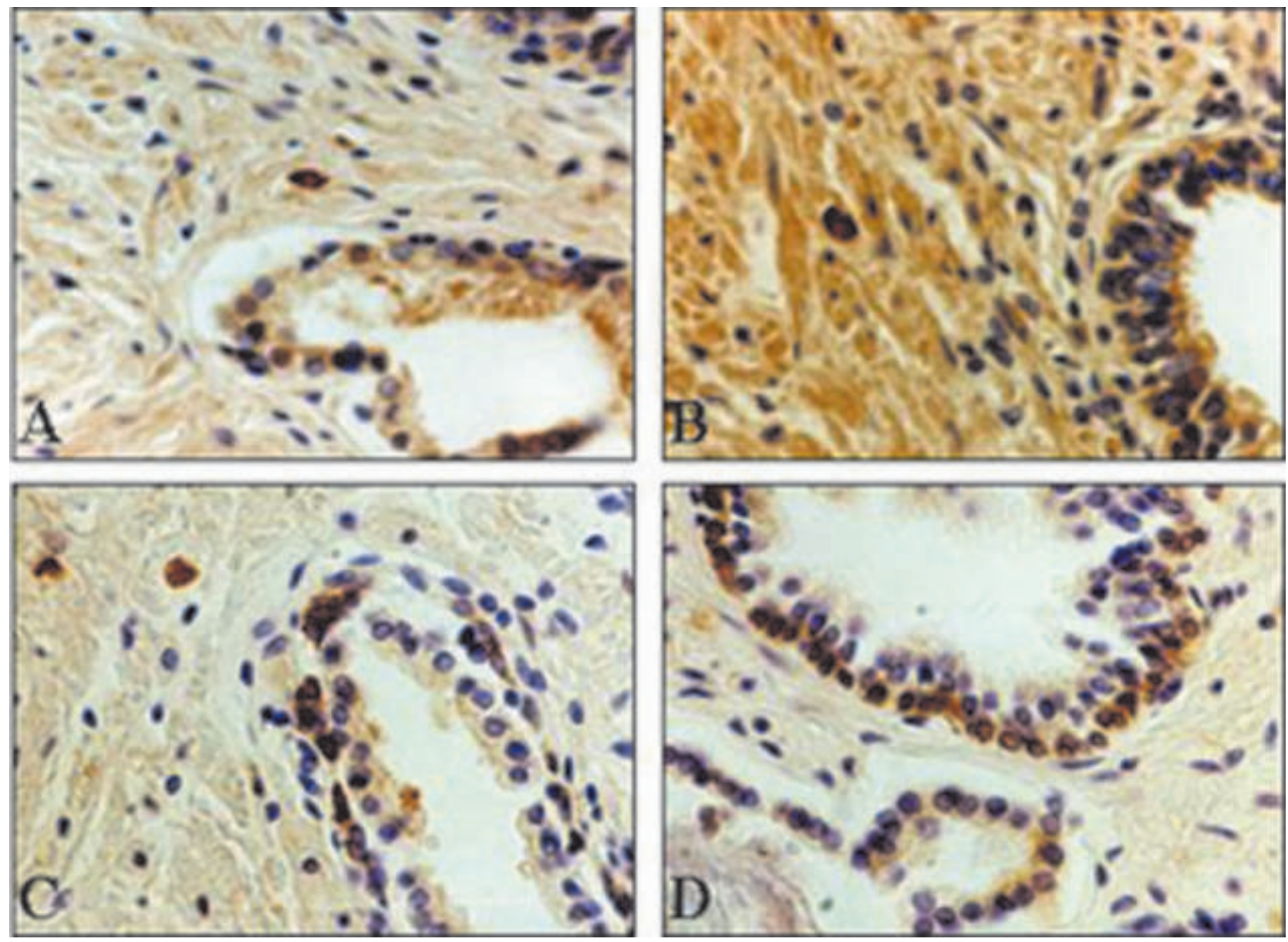

Figure 1. Immunohistochemistry showing ANF and oxytocin localisation in normal and hyperplastic prostate. A) ANF in normal; B) ANF in hyperplasia; C) oxytocin in normal; D) oxytocin in hyperplasia. Magnification 10×. See text for more details.

prostatic hyperplasia, we have studied the presence and the localisation of ANF in normal and hyperplastic human prostates, in order to clarify the possible role of this hormone in this organ and to investigate its possible functional interactions with the oxytocin.

\section{Materials and Methods Specimen collection}

Normal and hyperplastic prostatic tissues were obtained at the Institute of Urology of the Policlinico P. Giaccone of the University of Palermo, Italy. Differential diagnoses between normal and nodular hyperplasia were performed on 7-micra Bouin's liquid-fixed, paraffin-embedded, H\&Estained sections. We collected ten biopsies from both normal and hyperplastic prostates. Immuno-

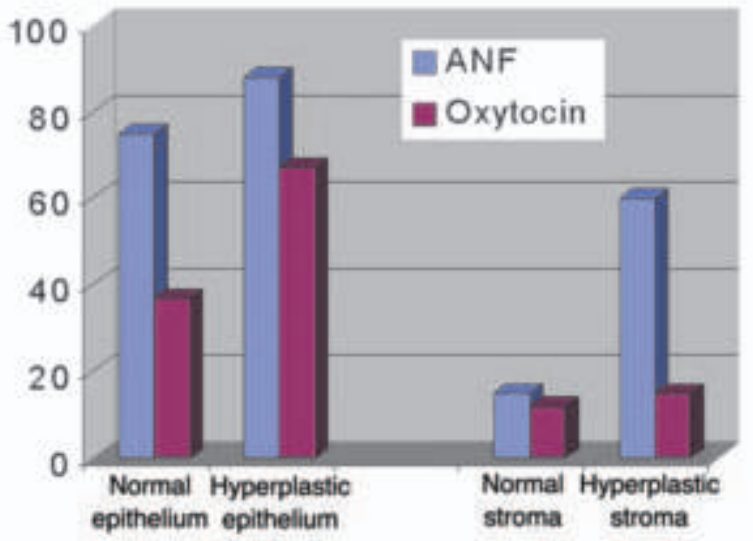

Figure 2. Graph showing the different expression of ANF and oxytocin in both epithelium and stroma of normal and hyperplastic prostates. See text for more details. 


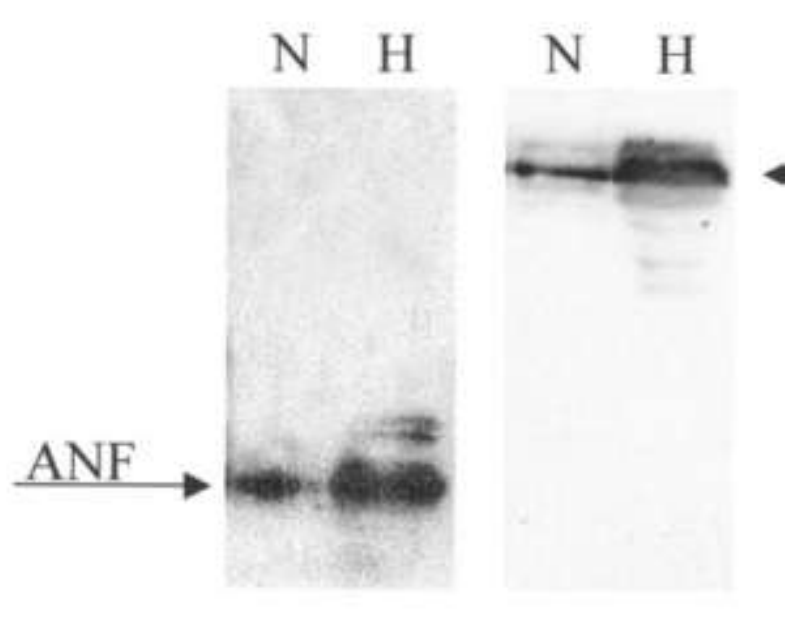

Figure 3. Western blot analysis showing an increase of both ANF and oxytocin, from normal to hyperplastic prostate. N: normal; H: hyperplastic; OT: oxytocin. See text for more details.

histochemical analyses were performed on Bouin's liquid-fixed paraffin-embedded tissues; moreover, a small specimen of each biopsy was frozen for Western blotting study, as described below.

\section{Immunohistochemistry}

Immunostaining by the streptavidin-biotin complex method (LSAB2 kit peroxidase, DAKO Corporation, Carpinteria CA, Cat. No K0677) was performed using monoclonal antibodies against ANF at the dilution of 1:500 (Cymbus Biotechnology LTD, Cat. No. CBL66) or against oxytocin at the dilution of 1:1000 (Chemicon, Cat. No. AB911) on $5 \mu$-thick sections after Bouin's fixation and paraffin embedding; isotype-matched controls were also used. After incubation for 10 min with protein block serum-free (DAKO Corporation, USA, Cat. No X0909), the primary antibody was added to the sections. DAB was used as develop chromogen (DAKO Corporation, Cat. No K3467). Hematoxylin aqueous formula (DAK0 Corporation, Cat. No S2020) was used as counterstaining. Results were semiquantitated by two independent observers, according to the cell percentage presenting immunopositivity.

\section{Western Blot analysis}

Twenty $\mu \mathrm{g}$ of total cell extracts to each lane and a protein marker (Kaleidoscope prestained standard, Bio-Rad, Hercules CA, USA, Cat. No 1610324) were separated by electrophoresis on denaturing $18 \%$ polyacrylamide slab gel (SDSPAGE) and transferred to nitrocellulose membrane (Nitrocell Paper, Bio-Rad, Hercules CA, USA, Cat. No 1620115). After 1 hour at room temperature with a blocking buffer ( $5 \%$ low-fat dried milk in TBST: $50 \mathrm{mM}$ Tris- $\mathrm{HCl} \mathrm{pH} 7.5,150 \mathrm{mM} \mathrm{NaCl}$, $0.1 \%$ Tween-20) under gentle shaking, the membrane was incubated with anti-ANF primary antibody (Cymbus Biotechnology LTD, Cat. No. CBL66) at the dilution of 1:500, overnight at $4{ }^{\circ} \mathrm{C}$. After washing, the membrane was incubated with HRP-conjugated secondary antibody (anti-mouse, Pierce, 1:5000, Cheshire UK, Cat. No 31432) for 1 hour at room temperature with shaking and the specific binding was detected using a chemiluminescent substrate (SuperSignal West Pico Chemiluminescent Substrate, Pierce, Cheshire UK, Cat. No 34080) for autoradiography.

The same procedure was performed for oxytocin analysis, using a denaturating $18 \%$ polyacrylamide slab gel, primary antibody anti-oxytocin at a dilution of $1: 1000$, and secondary anti-mouse antibody at a dilution of $1: 10000$.

\section{Statistical analysis}

Standard statistical analyses were applied to calculate the means and the standard deviation. A one way analysis of variance (ANOVA) was used to determine the presence of differences within the data obtained by immunostaining. Differences between the means were regarded as significant when a value of $p<0.05$ was obtained.

\section{Results}

Normal prostates showed classic tubulo-acinar units lined by simple columnar epithelium and a few basal cells surrounded by fibromuscular stroma; prostatic concretions (corpora amylacea) were sometimes present in the lumens. By contrast, hyperplastic prostates were characterised by hyperplasia of both glandular and stromal components; glands were dilated and epithelium ranged from columnar to flat; papillary infoldings were frequently present.

Immunostaining for ANF was positive in all normal and hyperplastic prostates. In particular, normal tissue showed cytoplasmic positivity of ANF in glandular cells more than in stromal cells (Figure la); indeed, ANF resulted positive in $75 \%$ of glandular cells and in $15 \%$ of stromal cells. Finally, ANF glandular positivity was present in both basal 
and columnar cells. By contrast, we found a higher positivity for ANF in nodular hyperplasia (Figure lb); in particular, $88 \%$ of epithelial- and $60 \%$ of stromal cells presented cytoplasmic positivity for ANF. We found statistically significant differences $(p<0.01)$ comparing stromal positivity in normal and hyperplastic stroma; by contrast, differences between positivity in normal and hyperplastic epithelium were statistically not significant ( $p>$ 0.05) (Figure 2).

Immunostaining for oxytocin resulted positive in glands of both normal and hyperplastic specimens (Figures 1c, d). In particular, oxytocin positivity was present in $37 \%$ of normal glandular cells and $67 \%$ of hyperplastic glandular cells and we found these data statistically significant $(p<0.02)$. By contrast, the percentages of stromal cells presenting oxytocin positivity were $12 \%$ in normal and $15 \%$ in hyperplastic tissues; these data were not statistically significant ( $p>0.05)$ (Figure 2$)$. The immunohistochemical observations were supported by Western blot analysis, which showed a lower expression of ANF and oxytocin in normal specimens, compared to the higher expression of these peptides in hyperplasia (Figure 3 ).

\section{Discussion}

Oxytocin is a peptide secreted by the hypothalamic magnocellular neurosecretory system, and ANF is a peptide first extracted from atrial granules but is also found in other sites such as ventricular myocardiocytes (Yamada et al., 1988), the conduction system (Sola et al., 1990), atrioventricular valves (Valentino et al., 1995), the excretory system of kidney (McKenzie et al., 1991), the pancreas (Chabot et al., 1987) and the salivary glands (Valentino et al. 1999). In particular, we have recently demonstrated the presence of ANF in the rabbit parotid gland and postulated that it may play a role in the acinary cells and intralobular ducts, suggesting its involvement in the composition of saliva. Moreover, ANF was present in the extralobular ducts and in the stromal vessels, being possibly involved in salivary fluidity (Valentino et al. 1999). Recent evidence supports a paracrine interaction between ANF and oxytocin, at different sites. Haanwinckel et al. (1995) found that oxytocin released from the neurohypophysis increased the plasma concentration of ANF which, in turn, induced natriuresis and diuresis. Moreover, Gutkowska et al. (1997) showed that oxytocin bound to its receptors in myocardiocytes and induced the release of ANF via a CGMP-mediated mechanism, determining a rapid reduction of circulating blood volume. In addition, Soares et al. (1999) demonstrated an oxytocin-mediated natriuretic action of ANF in renal tubules, with an increase of cGMP concentration.

In the present study, we described the presence and the localisation of ANF and oxytocin in normal and hyperplastic human prostate. In the normal prostate, we found ANF-immunopositive cells in both glands and stroma. Because it is known that ANF induces electrolyte and water transport, we thought that the ANF present in glandular cells could have a role in the electrolytic composition of prostatic fluid, analogously to that in the parotid gland (Valentino et al., 1999). Moreover, the ANF present in the stromal cells adjacent to the periglandular vessels could regulate the muscular tone of these vessels, inducing vasodilatation and regulating the fludity of prostatic liquid.

ANF-immunopositivity was increased in hyperplastic prostate, as shown by immunohistochemistry and confirmed by Western blot analysis; this increase was different between epithelial and stromal cells. In fact, we showed a modest increase of ANF-positive glandular cells in hyperplasia, compared to normal prostate tissue, while stroma presented a strong ANF positivity. An increase in oxytocin was also noticed in the hyperplastic prostate with the increase being found mainly in epithelial cells.

Since both ANF and oxytocin are increased in hyperplastic tissue, a relationship between these hormones may be hypothesized, as, in fact, has been shown in other organs. In particular, a paracrine action of oxytocin on the ANF-positive cells may be presumed, as has already been demonstrated in the heart (Gutkowska et al., 1997); indeed, ANF overexpression in hyperplastic prostates could be induced by oxytocin, via a paracrine mechanism. Moreover, many authors have clarified the role of oxytocin in the pathogenesis of nodular hyperplasia. In particular, the expression of oxytocin receptors on glandular cells of prostate is regulated by androgens, such as testosterone, and oxytocin could have a paracrine action on epithelial cells, inducing prostatic growth (Frayne and Nicholson 1998; Nicholson and Jenkin, 1995). Therefore, the increase in glandular oxytocin-positive cells seems to be related to prostatic hyperplasia. Similarly, the 
statistically significant increase in ANF in stromal cells of the hyperplastic prostates might also be related to prostatic hyperplasia. Lee et al (1988) reported that ANF binds with high affinity to ANF receptors on human fibroblasts; this led us to postulate that ANF also has a paracrine action on prostatic fibroblasts. As a consequence, it is possible that the peptides have different roles in the pathogenesis of prostatic hyperplasia: oxytocin could induce the growth of glandular tissue; ANF could stimulate the growth of the stromal component.

In conclusion, to our knowledge, this is the first report demonstrating ANF positivity and localisation in normal and hyperplastic prostates; we postulate that it plays a physiological role in the secretion of prostatic fluid and we suspect a probable implication in prostatic hyperplasia pathogenesis; however, at this stage, the existence of this interaction needs further confirmation.

\section{References}

Agalba F. Bases morfologicas del desarollo de la hiperplasia prostatica. Patologia 1993;26:113-9.

Atarashi K, Mulrow PJ, Franco-Saenz K, Snajdar R, Rapp J. Inhibition of aldosterone production by an atrial extract. Science 1994; 224 : 992-4.

Bodanszky M, Sharaf H, Roy JB, Said SI. Contractile activity of vasotocin, oxytocin and vasopressin on mammalian prostate. Eur J Pharmacol 1992;216:311-3.

Burnett JD Jr, Granger JP, Opgenorth TJ. Effects of synthetic atrial natriuretic factor on renal function and renin release. Am J Physiol 1984;247:F863-6.

Carvajal JA, Aguan K, Thompson LP, Buhimschi IA, Weiner CP. Natriuretic peptide-induced relaxation of myometrium from the pregnant guinea pig is not mediated by guanyilate cyclase activation. J Pharmacol Exp Ther 2001;297:181-8.

Chabot JG, Morel G, Kopelman H, Belles-Islet M, Heisler S. Atrial natriuretic factor and exocrine pancreas: autoradiographic localisation of binding sites and ultrastructural evidence for internalization of endogenous ANF. Pancreas 1987;2:404-13.

Currie MG, Geller DM, Cole BR, Boyland JG, Sheng WY, Homberg SW, et al. Bioactive cardiac substances: potent vasorelaxant activity in mammalian atria. Science 1983;221:71-3.

Favaretto AL, Ballejo G0, Albuquerque-Araujo WI, Gutkowska J, Antunes-Rodrigues J, McCann SM. Oxytocin releases atrial natriuretic peptide from atria in vitro that exerts negative inotropic and chronotropic action. Peptides 1997;18:1377-81.

Frayne J, Nicholson HD. Localization of oxytocin receptors in the human and macaque monkey male reproductive tracts: evidence for a physiological role of oxytocin in the male. Mol Hum Reprod 1998; 4:527-32.

Gutkowska J, Jankowski M, Lambert C, Mukaddam-Daher S, Zingo $\mathrm{HH}, \mathrm{McC}$ ann S. Oxytocin releases atrial naytriuretic peptide by combining with oxytocin receptors in the heart. Proc Natl Acad Sci USA 1997;94:11704-9.

Haanwinckel MA, Elias LK, Favaretto ALV, Gutkowska J, McCann SM. Oxytocin mediates atrial natriuretic peptide release and natriuresis after volume expansion in the rat. Proc Natl Acad Sci USA 1995;92:7902-6.

Lee MA, West RE Jr, Moss J. Atrial natriuretic factor reduces cyclic adenosine monophosphate content of human fibroblasts by enhancing phosphodiesterase activity. J Clin Invest 1988;82:388-93.

Mc Kenzie JC, Scott J, Inagami T. Immunohistochemical localization of atrial natriuretic peptide in the developing and adult mammalian kidney. Am J Anat 1991;190:182-91.

Nicholson HD. Oxytocin: a paracrine regulator of prostatic function. Rev Reprod 1996;1:69-72.

Nicholson HD, Jenkin L. Oxytocin and prostatic function. Adv Exp Med Biol 1985;395:529-38.

Pandey $\mathrm{KN}$, Orgebin-Crist M. Atrial natriuretic factor in mammalian testis: immunological detection in spermatozoa. Biochem Biophys Res Comm 1991;180:437-44

Samson W. Atrial natriuretic factor inhibits dehydration and hemorrhage-induced vasopressin release. Neuroendocrinology 1985; 40: 277-9.

Soares TJ, Coimbra TM, Martins AR, Pereira AGF, Carnio EC, Branco LGS, et al. Atrial natriuretic peptide and oxytocin induce natriuresis by release of cGMP. Proc Natl Acad Sci USA 1999;96:278-83.

Sola C, Thibault G, Haile-Meskel H, Anad-Srivastava MB. Atrial natriuretic factor in the vena cava and sinus node. J Histochem Cytochem 1990;38123-35.

Valentino $B$, Farina $E$, Ridola $C$. Immunohistochemical research on the atrial natriuretic factor (ANF) in rat atrio-ventricular valves. It $\mathrm{J}$ Anat Embryol 1995;100:65-75.

Valentino B, Farina Lipari $E$, Carini $F$, Valenza V. Immunohistochemical localization of atrial natriuretic factor (ANF) in the excretory system of the rabbit parotid gland. Eur J Histochem 1999;43: 241-5.

Yamada H, Saito Y, Mukoyama M, Nakao K, Yasue H, Ban T, et al. Immunohistochemical localization of atrial natriuretic polypeptide (ANP) in human atrial and ventricular myocardiocytes. Histochemistry 1988;89:411-3. 
E. Farina-Lipari et al. 